\title{
Assessment of Oral Health in Elders with and without Alzheimer's Disease: A Cross-Sectional Study
}

\author{
Ilgin Asena Cebeci ${ }^{1}$, Damla Ozturk ${ }^{2}$, Basak Dogan ${ }^{2}$, Nural Bekiroglu ${ }^{3}$ \\ ${ }^{1}$ Department of Biostatistics, Institute of Health Sciences, Marmara University, Istanbul, Turkey. \\ ${ }^{2}$ Department of Periodontology, Faculty of Dentistry, Marmara University, Istanbul, Turkey. \\ ${ }^{3}$ Department of Biostatistics, School of Medicine, Marmara University, Istanbul, Turkey. \\ Correspondence Author: Ilgin Asena Cebeci \\ E-mail: ilgincebeci@gmail.com
}

Received: 17.08.2021 Accepted: 07.09.2021

\begin{abstract}
Objective: The aim of the study was to assess and compare the oral health status in elders with and without Alzheimer's disease (AD).

Methods: This age and gender-matched cross-sectional study included thirty-six elders with AD and 37 elders without AD from an Alzheimer's daycare center and a nursing home. Mental state, oral health and periodontal parameters, Geriatric Oral Health Assessment Index (GOHAI), unstimulated salivary flow rate (USFR), and other dry mouth conditions were examined. Group comparisons and correlation analysis were performed with T-test, Mann-Whitney U test, chi-square test, Fisher's Exact test, and Spearman's rank correlation.

Results: Probing depth (PD) and clinical attachment loss (CAL) were lower and the percentage of the subjects with non-periodontitis was higher in elders with $A D$ than without $A D$ ( $p=0.017$ and $p=0.028$, respectively). Both groups had similar GOHAI scores and USFR levels ( $p>0.05$ ). However, the elders with $A D$ had higher use of mouth-drying medication and presence of halitosis complaint than without $A D$ ( $p<0.001)$. In both groups number of missing teeth was positively correlated with the DMF-T score ( $p<0.001)$. In AD group, age was positively related to the gingival index and bleeding on probing ( $p=0.005$ and $p=0.001$, respectively). USFR level was positively correlated with $G O H A I$ score ( $p=0.027)$ in AD group, but it was negatively correlated with the DMF-T score $(p=0.031)$ in without AD group.
\end{abstract}

Conclusion: Personalized care and supporting oral care education of the caregivers could maintain the oral health of elders with AD.

Keywords: Alzheimer disease, oral health, quality of life, dementia, periodontitis

\section{INTRODUCTION}

Alzheimer's disease $(A D)$ is one of the main causes of dementia in the geriatric population which represents more than half of the dementia cases. The disease is a progressive neurodegenerative disease of the central nervous system $(1,2)$. Impaired memory and failure to learn new information are the most prominent clinical features of the disease. Despite the memory loss in the early stage of the disease, the patient can continue his daily life activities independently. In the middle stage of the disease, the independence in daily living activities is gradually lost, and psychiatric and behavioral symptoms begin to appear. In the last stage of the disease, the patient becomes completely dependent on his caregiver in daily living activities, and serious psychiatric disorders may occur (1).

Various risk factors are associated with $A D$. The incidence of $A D$ increases with older age, lower education, and female gender. Also hereditary, and environmental factors play a role in the etiology of the disease. History of previous head injury has also been linked with the increased risk of developing $A D(3)$. It has been reported that the incidence of the disease increases in case of blood vessel damages due to hypertension, heart disease, stroke, and diabetes. (4).

Oral health problems are frequently seen because of the behavioral effects of dementia, which could make it difficult for a patient to perform oral care (5). The deterioration of oral, and dental care lead to plaque accumulation, and dental caries (6). Also, dementia patients suffer from gingival bleeding, periodontal pockets, mucosal lesions, and reduced salivary flow. Elders with dementia experience poor oral health, which can be improved with an oral care education for caregivers, and regular professional dental care of the patients (7). However dental treatment of $A D$ patients becomes challenging due to their reduced ability to cooperate (8).

Periodontal disease is an inflammatory status that could lead to tooth loss when it is left untreated (9). The disease is known to be linked with many systematic diseases. Recent 
findings showed that the periodontal pathogens' effect on neural inflammation could lead to cognitive decline, and sporadic late-onset AD (10).

Dry mouth is another factor affecting the oral health of individuals, especially in AD. Sreebny and Schwartz reported that $80 \%$ of the commonly prescribed drugs cause dry mouth, and more than 400 drugs cause salivary gland dysfunction as a side effect (11). Thus, the dysfunction in the antibacterial effect of saliva leads to disorders such as lack of lubricant, and buffering function, caries and periodontal disease, difficulty in chewing and swallowing $(12,13)$.

The aim of this study is to compare the oral health of elders with and without $A D$, through oral examination, oral health quality of life assessment, and evaluation of dry mouth condition.

\section{METHODS}

This cross-sectional study was conducted in January 2018 - March 2019 in Istanbul, Turkey. A group of 73 elders participated in the study, 36 elders with $A D$, and 37 elders without $A D$. Firstly elders with $A D$ were recruited, and the elders without $A D$ were matched for age and gender. Nineteen of the elders with $A D$ were living in the home with their family or caregivers and visiting the daycare center of the Turkish Alzheimer Association few days a week, where caregivers were educated on caring for the elders. The remaining 17 elders with $A D$ and elders without $A D$ were living in a public nursing home. Socio-demographic characteristics and use of medications were obtained via a questionnaire. The medications that cause dry mouth were determined from Sreebny and Schwartz's work (11). The oral health quality of life was examined with the Turkish version of the Geriatric Oral Health Assessment Index (GOHAI) (14). Elders with $A D$ responded to the questionnaire and GOHAI with their caregivers, while elders without $A D$ responded by themselves.

This study was conducted according to the guidelines of the Declaration of Helsinki and approved by the Ethical Committee of Marmara University School of Medicine (protocol number 09.2018.056/05.01.2018). Written informed consent has been obtained from the caregivers of the elders with $A D$, and the elders without AD involved in the study.

\subsection{Mental State Evaluation}

Participants' mental state was evaluated with the MiniMental State Examination test (MMSE). The test score was categorized as normal (between 24 and 30), mild or moderate dementia (between 23 and 18), and severe dementia (17 or lower) (15).

\subsection{Oral and Periodontal Examination}

The periodontal assessments were carried out for those who were dentate and gave consent for the examination
(23 elders with AD patients and 24 elders without AD). The oral and prosthesis care habits and halitosis complaints were recorded. The oral and periodontal examination was performed by a single dentist (DO) using the University of North Carolina 15 periodontal probe (Hu-Friedy, Chicago, IL), and a dental mirror. The decayed, missing, filled teeth (DMF-T) index (16), prosthetic situation, modified mucosal rating scale (MMRS) (17) were assessed. Plaque index (PI) (18), gingival index (GI) (19), probing depth (PD), bleeding on probing (BOP), and clinical attachment loss (CAL) (16) were recorded. Periodontal status was determined according to the Centers for Disease Control and Prevention-American Academy of Periodontology criteria set in 2012 (20).

\subsection{Geriatric Oral Health Assessment Index}

Geriatric Oral Health Assessment Index (GOHAI) is a 12-items scale, which evaluates the elders' oral health quality of life (21). Participants respond how often they experience a specific oral health issue stated in the item based on a 5-point Likert scale (1-always and 5-never). The total score was computed as the sum of item scores and ranges from 12 to 60 . A higher GOHAl score indicates a better oral health quality of life (14). The scale has four dimensions which are functional restriction (eating, speaking, and swallowing), pain or discomfort (use of medication to relieve pain, eating without discomfort, and sensitivity to hot, cold, or sweets), psychological factors (worry or concern about oral health, dissatisfaction with appearance, self-consciousness about oral health, and feel uncomfortable eating in front of people), and behavioral effects (limiting the amount and kind of food, and avoidance of social contacts because of oral problems) (21).

\subsection{Unstimulated Saliva Collection}

The unstimulated saliva collection was performed at least one hour after the participant's food and beverage intake, except for water. The participants were requested to sit upright, not to swallow, and lean their head forward over a measuring cup to let the saliva drain in it. A one-minute pretest was performed, and the saliva collection trial lasted for five minutes. The unstimulated salivary flow rate (USFR) was computed by dividing the saliva level into collection period ( $\mathrm{ml}$ per $\mathrm{min}$ ). A value lower than $0.1 \mathrm{ml}$ per min was considered as salivary gland hypofunction (22).

\subsection{Statistical Analysis}

The descriptive statistics were reported as frequency ( $n, \%)$ for the discrete random variables. The continuous random variables were presented as mean and standard deviation (SD) when the data follow a normal distribution, otherwise reported as the median and interquartile range (IQR). The group comparisons between the elders with and without AD were evaluated with independent samples $T$-test, MannWhitney $U$ test, Chi-square test, and Fisher's Exact test. Spearman's rank correlation analysis was performed for 
each group. The statistical significance level was considered as $p<0.05$, and the analysis was carried out with IBM SPSS Statistics for Windows, version 26.0 (IBM Corp., Armonk, N.Y., USA).

\section{RESULTS}

The participant characteristics of the study groups are presented in Table 1. The mean age was $77.1( \pm 9.7)$ for elders with $A D$, and $77.4( \pm 7.8)$ for elders without $A D(p=0.876)$. The mean age onset for $A D$ was $72.6( \pm 10.6)$ years. Almost half of the elders with $\operatorname{AD}(17,47.2 \%)$, and without $A D(18,48.7 \%)$ were female $(p=0.903)$. There was no statistically significant difference between elders with and without $A D$ in terms of education level $(p=0.667)$, and smoking habit $(p=0.226)$. More than half of the elders with $A D$ were cared in-home and daycare center by their family or/and a personal caregiver
$(19,52.8 \%)$. The remaining elders with $\operatorname{AD}(17,47.2 \%)$, and all elders without $A D$ cared in the nursing home $(p<0.001)$ (Table 1).

The elders with $A D$ group had a significantly lower median MMSE score than the elders without AD group $(p<0.001)$. Severe dementia $(20,55.6 \%)$ was observed in more than half of the elders with $A D$, while the remaining $(16,44.4 \%)$ had mild or moderate dementia. The median number of medications that cause dry mouth condition was higher in the elders with $A D$ than the elders without $A D(p<0.001)$. The use of neurotransmitter $(p=0.358)$, antiepileptic $(p=0.615)$, cardiovascular disease treatment $(p=0.879)$, antidiabetic $(p=0.113)$ medications were similar between the elders with and without $A D$ groups. However, the elders with $A D$ had more frequent use of nonsteroidal anti-inflammatory $(p=0.046)$, psychiatric $(p<0.001)$, and stomach $(p=0.028)$ medications than the elders without AD (Table 1).

Table 1. Inter-group comparisons of the participant characteristics

\begin{tabular}{|c|c|c|c|}
\hline $\begin{array}{l}\text { Socio-demographic } \\
\text { Parameters }\end{array}$ & Elders with $A D(n=36)$ & Elders without AD ( $n=37)$ & p-value \\
\hline Age years; mean $\pm S D$ & $77.1 \pm 9.7$ & $77.4 \pm 7.8$ & $0.876^{a}$ \\
\hline Age onset of the $A D$ years; mean $\pm S D$ & $72.6 \pm 10.6$ & - & \\
\hline Female $\mathrm{n}(\%)$ & $17(47.2 \%)$ & $18(48.7 \%)$ & $0.903^{b}$ \\
\hline \multicolumn{4}{|l|}{ Education level n (\%) } \\
\hline Illiterate & $7(19.4 \%)$ & $11(29.7 \%)$ & \\
\hline Primary school & $12(33.3 \%)$ & $12(32.4 \%)$ & \\
\hline Secondary school & $4(11.1 \%)$ & $6(16.2 \%)$ & \\
\hline High school & $6(16.7 \%)$ & $4(10.8 \%)$ & \\
\hline University & $7(19.4 \%)$ & $4(10.8 \%)$ & $0.667^{b}$ \\
\hline Smoking $\mathrm{n}(\%)$ & $4(11.1 \%)$ & $8(21.6 \%)$ & $0.226^{b}$ \\
\hline \multicolumn{4}{|l|}{ Place of Care $\mathrm{n}(\%)$} \\
\hline Home and day care center & $19(52.8 \%)$ & - & \\
\hline Spouse & $7(19.4 \%)$ & - & \\
\hline Adult children & $9(25.0 \%)$ & - & \\
\hline Family and personal caregiver & $3(8.3 \%)$ & - & \\
\hline Nursing home & $17(47.2 \%)$ & $37(100.0 \%)$ & \\
\hline MMSE (points; median (IQR) & $16.5(11.5-20.0)$ & $28.0(28.0-29.0)$ & $<0.001^{d}$ \\
\hline \multicolumn{4}{|l|}{ Mental Status n (\%) } \\
\hline Normal mental status & - & $37(100 \%)$ & \\
\hline Mild or Moderate dementia & $16(44.4 \%)$ & - & \\
\hline Severe dementia & $20(55.6 \%)$ & - & \\
\hline $\begin{array}{l}\text { Number of medications that cause dry } \\
\text { mouth median (IQR) }\end{array}$ & $4.0(2.0-5.0)$ & $1.0(1.0-2.0)$ & $<0.001^{d}$ \\
\hline \multicolumn{4}{|l|}{ Use of Medication $n(\%)$} \\
\hline NSAI drugs & $8(22.2 \%)$ & $2(5.4 \%)$ & $0.046^{c}$ \\
\hline Neurotransmitter drugs & $3(8.3 \%)$ & $1(2.7 \%)$ & $0.358^{c}$ \\
\hline Psychiatric drugs & $29(80.6 \%)$ & $3(8.1 \%)$ & $<0.001^{b}$ \\
\hline Antiepileptic drugs & $2(5.6 \%)$ & $1(2.7 \%)$ & $0.6150^{c}$ \\
\hline Cardiovascular disease treatment drugs & $23(63.9 \%)$ & $23(62.2 \%)$ & $0.8790^{b}$ \\
\hline Antidiabetic drugs & $9(25.0 \%)$ & $4(10.8 \%)$ & $0.113^{b}$ \\
\hline Stomach drugs & $10(27.8 \%)$ & $3(8.1 \%)$ & $0.028^{b}$ \\
\hline
\end{tabular}


The oral and periodontal findings of the study groups are presented in Table 2. More than one-third of elders with $\operatorname{AD}(12,33.3 \%)$ and elders without $\operatorname{AD}(13,35.1 \%)$ were edentulous $(p=0.871)$. The prosthesis type used in the upper jaw and lower jaws were similar between the study groups $(p>0.05)$. Oral and prosthetic care of the groups were also similar, almost $60 \%$ of the elders practice oral care at least once a day in both groups $(p=0.732)$ (Table 2$)$.

Table 2. Inter-group comparisons of the oral and periodontal findings

\begin{tabular}{|c|c|c|c|}
\hline Oral Health Finding & $\begin{array}{l}\text { Elders with AD } \\
\qquad(\mathrm{n}=36)\end{array}$ & $\begin{array}{l}\text { Elders without } A D \\
\qquad(n=37)\end{array}$ & p-value \\
\hline Edentulousness $\mathrm{n}(\%)$ & $12(33.3 \%)$ & $13(35.1 \%)$ & $0.871^{c}$ \\
\hline \multicolumn{4}{|l|}{ Upper jaw prosthesis type ${ }^{a} \mathrm{n}(\%)$} \\
\hline Complete denture & $21 / 31$ & $22 / 28$ & $0.350^{c}$ \\
\hline Removable partial denture & $6 / 31$ & $5 / 28$ & $0.883^{c}$ \\
\hline Fixed prosthesis & $4 / 31$ & $1 / 28$ & $0.199^{c}$ \\
\hline \multicolumn{4}{|l|}{ Lower jaw prosthesis type ${ }^{\mathrm{a}} \mathrm{n}(\%)$} \\
\hline Complete denture & $15 / 29$ & $17 / 28$ & $0.494^{c}$ \\
\hline Removable partial denture & $9 / 29$ & $11 / 28$ & $0.173^{c}$ \\
\hline Fixed prosthesis & $5 / 29$ & $0 / 28$ & $0.052^{d}$ \\
\hline \multicolumn{4}{|l|}{ Oral and prosthesis care $n(\%)$} \\
\hline Less than twice a week & $11(30.6 \%)$ & $12(32.4 \%)$ & \\
\hline At least twice a week & $5(13.9 \%)$ & $3(8.1 \%)$ & \\
\hline At least once a day & $20(55.6 \%)$ & $22(59.5 \%)$ & $0.732^{c}$ \\
\hline \multicolumn{4}{|l|}{ Modified Mucosal Rating Scale $\mathrm{n}(\%)$} \\
\hline Normal & $32(88.9 \%)$ & 34 (91.9\%) & \\
\hline Mild & $4(11.1 \%)$ & $3(8.1 \%)$ & $0.663^{c}$ \\
\hline DMF-T median (IQR) & $26.5(18.3-28.0)$ & $28.0(22.5-28.0)$ & 0.384 回 \\
\hline Decayed teeth & $0.0(0.0-0.0)$ & $0.0(0.0-0.5)$ & 0.352 [?] \\
\hline Missing teeth & $24.5(8.5-28.0)$ & $25.0(20.0-28.0)$ & 0.467 回 \\
\hline Filled teeth & $0.0(0.0-2.8)$ & $0.0(0.0-0.0)$ & 0.198 ? \\
\hline Number of Teeth & $3.5(0.0-19.5)$ & $3.0(0.0-8.0)$ & 0.467 回 \\
\hline PI? median (IQR) & $2.0(1.5-2.0)$ & $2.0(1.6-2.0)$ & 0.964 ? \\
\hline GI? median (IQR) & $1.4(1.3-1.8)$ & $1.4(1.3-1.7)$ & 0.476 回 \\
\hline BOP? \%; median (IQR) & $33.3(14.6-50.0)$ & $33.3(21.8-48.6)$ & 0.558 ? \\
\hline 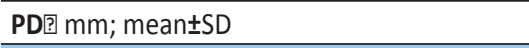 & $2.8 \pm 0.8$ & $3.3 \pm 0.6$ & 0.017 \\
\hline CAL? mm; median (IQR) & $3.1(2.5-5.3)$ & $4.3(3.3-5.7)$ & 0.028 ? \\
\hline \multicolumn{4}{|l|}{ Periodontal status? n (\%) } \\
\hline Non-periodontitis & $10 / 23$ & $2 / 24$ & $0.008^{d}$ \\
\hline Moderate Periodontitis & $8 / 23$ & $11 / 24$ & $0.440^{c}$ \\
\hline Severe Periodontitis & $5 / 23$ & $11 / 24$ & $0.081^{c}$ \\
\hline \multicolumn{4}{|l|}{ GOHAI } \\
\hline Total Score mean $\pm S D$ & $50.3 \pm 4.9$ & $49.7 \pm 4.5$ & 0.551 ? \\
\hline Functional Restriction Score median (IQR) & $14.0(11.0-15.0)$ & $13.0(11.0-15.0)$ & 0.463 回 \\
\hline Pain and Discomfort Score median (IQR) & $14.5(13.0-15.0)$ & $15.0(13.0-15.0)$ & 0.656 ? \\
\hline Psychological Factors Score median (IQR) & $15.0(14.0-17.0)$ & $14.0(13.0-17.5)$ & 0.249 圂 \\
\hline Behavioral Effects Score median (IQR) & $8.0(7.0-10.0)$ & $8.0(7.0-9.0)$ & 0.614 ? \\
\hline USFR ml/min; median (IQR) & $0.3(0.1-0.4)$ & $0.3(0.1-0.5)$ & 0.607 回 \\
\hline USFR $\geq 0.1 \mathrm{ml} / \mathrm{min} \mathrm{n}(\%)$ & $27(75.0 \%)$ & $31(83.8 \%)$ & - \\
\hline USFR <0.1 ml/min n (\%) & $9(25.0 \%)$ & $6(16.2 \%)$ & - \\
\hline Halitosis Complaint $\mathrm{n}(\%)$ & $24(66.7 \%)$ & $8(21.6 \%)$ & $<0.001^{\mathrm{c}}$ \\
\hline
\end{tabular}

${ }^{a}$ Analysis performed for those who wear prosthesis in the relevant jaw; 回 Assessment carried out for 23 AD patients and 24 elders without AD. [Chi-square test; [ Fisher's exact test; [ Mann-Whitney U test; [Independent samples T-test. Abbreviations; AD: Alzheimer's disease, DMF-T: Decayed missing filled teeth index score, IQR: Interquartile range, PI: Plaque index, GI: Gingival index, BOP: Bleeding on probing, PD: Probing depth, CAL: Clinical attachment loss, GOHAl: Geriatric Oral Health Assessment index, SD: Standard deviation, USFR: Unstimulated salivary flow rate. 
Most of the elders with and without AD had normal MMRS $(p=0.663)$. The Median DMF-T index score was relatively high in both elders with $A D(26.5$, IQR:18.3 - 28.0) and without AD (28.0, IQR:22.5 - 28.0) groups $(p=0.384)$. Both study groups had similar number of teeth $(p=0.467), P I(p=0.964)$, GI $(p=0.476)$, and BOP $(p=0.5580)$. The mean PD and median CAL were significantly lower in elders with $A D$ than elders without $A D(p=0.017$ and $p=0.028$, respectively). Patients having non-periodontitis were higher in $A D$ group than the elders without $A D(p=0.008)$. All participants had a relatively high mean GOHAI score of 50 points (out of 60), which was similar between the groups $(p=0.551)$. The median USFR level was $0.3 \mathrm{ml} / \mathrm{min}$ for elders with and without AD ( $p=0.607)$. About $25 \%$ of elders with $A D$ and $16 \%$ of elders without $A D$ had a median USFR level below $0.1 \mathrm{ml} / \mathrm{min}$. Elders with $A D$ had more frequently complained about halitosis than those without $A D(p<0.001)$ (Table 2).

Correlation analysis between age, GOHAl scores, and selected oral health and periodontal findings of study groups was presented in Table 3. In both study groups, the higher number of missing teeth was positively correlated with DMF-T score $(p<0.001)$.
In elders with $A D$ the higher age was associated with the higher number of missing teeth $(r=0.44, \mathrm{p}=0.007), \mathrm{GI}(r=0.57$, $\mathrm{p}=0.005)$, and BOP $(r=0.66, p=0.001)$. The higher GOHAI score was correlated with the higher level of USFR ( $r=0.37$, $\mathrm{p}=0.027)$. Also, the higher GOHAI pain and discomfort score was associated with the lower GI $(r=-0.45, p=0.031)$. The higher GOHAI psychological factors score was correlated with the lower PD $(r=-0.49, \mathrm{p}=0.018)$ and CAL $(r=-0.48, \mathrm{p}=0.020)$. The lower GOHAI behavioral effects score was associated with the higher BOP (\%) $(r=-0.46, \mathrm{p}=0.029), \mathrm{PD}(r=-0.42, \mathrm{p}=0.044)$ and CAL $(r=-0.53, p=0.009)$ in elders with AD. The number of missing teeth and DMF-T score were positively correlated with BOP, PD, and CAL ( $p<0.01$ ) in AD group. (Table 3$)$.

In elders without AD higher DMF-T score was negatively correlated with GOHAl total score $(r=-0.41, p=0.011)$, GOHAl behavioral effects score $(r=-0.36, p=0.028)$, and USFR level ( $r=-0.36, \mathrm{p}=0.031)$. The higher CAL was positively correlated with GOHAl functional restriction score $(r=0.41$, $\mathrm{p}=0.050)$, and USFR $(r=0.42, \mathrm{p}=0.042)$ in elders without $A D$. (Table 3).

Table 3. Correlation between age, GOHAl scores, and selected oral health and periodontal parameter findings of study groups

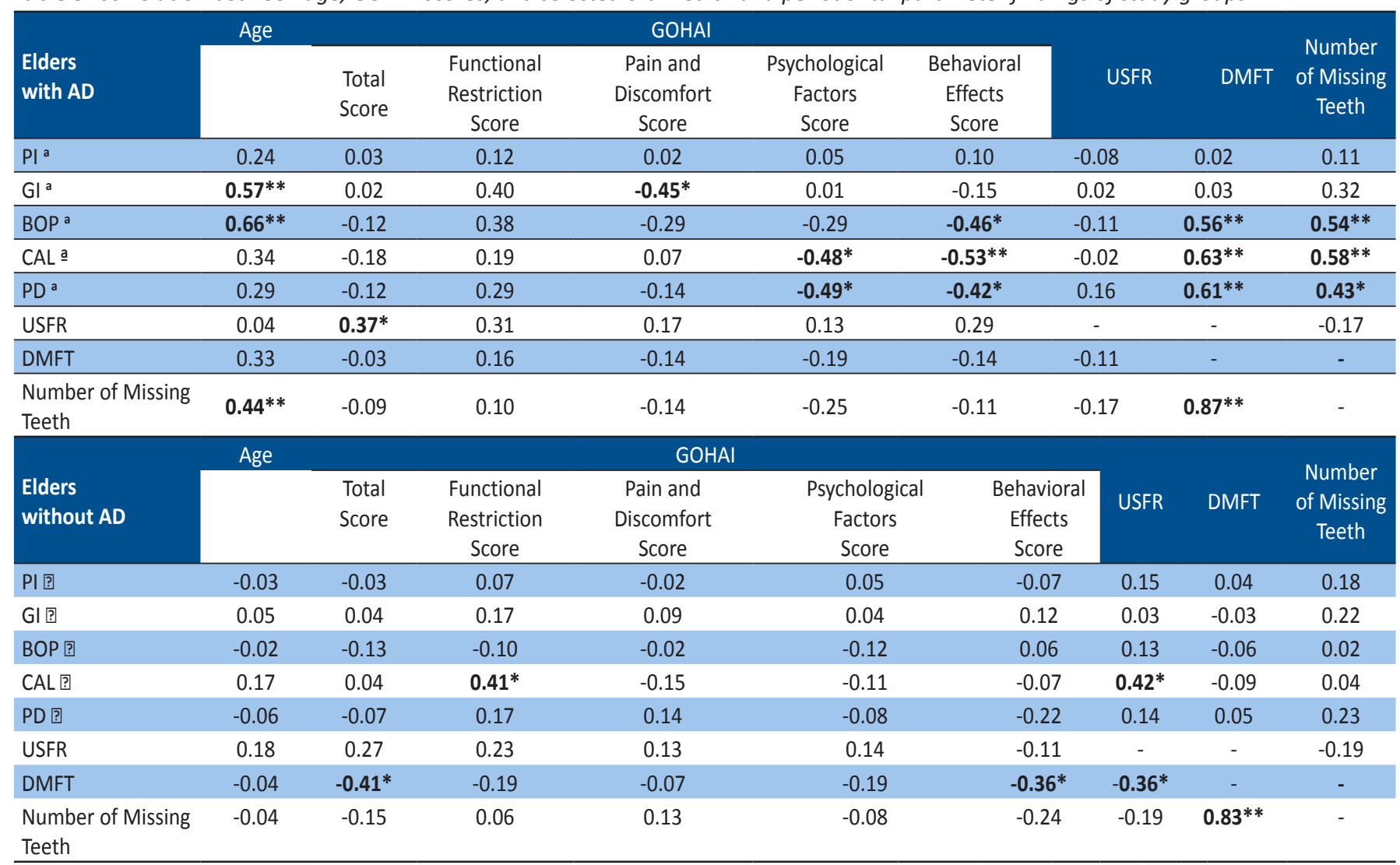

Spearman's rank correlation test significant at ${ }^{*} p<0.05$ and ${ }^{* *} p<0.01$ level. Analysis performed for a $n=23$ and $n=24$. Abbreviations; AD: Alzheimer's Disease, GOHAl: Geriatric Oral Health Assessment index, PI: Plaque index, GI: Gingival index, BOP: Bleeding on Probing, PD: Probing depth, CAL: Clinical attachment IOSS, USFR: Unstimulated salivary flow rate, DMF-T: Decayed missing filled teeth index score. 


\section{DISCUSSION}

In this cross-sectional study, oral and periodontal health, the oral health quality of life, and the dry mouth condition of the elders with and without AD were investigated. The participants were recruited on a voluntary basis from two different institutions by matching for age and gender. The edentulousness was not significantly different between elders with and without AD. Both group participants mostly use complete prosthetics, and the type of prosthesis use was similar between the study groups. These findings agree with the findings of previous studies $(23,24)$.

The self-rated GOHAl scores were found relatively high, and there was no significant difference between the comparison groups, this finding is consistent with the study of Ribeiro et al. (23), and a recent systematic review (25). Although most of the elders with $A D$ in our study were suffering from poor oral health conditions, GOHAl scores were reported relatively high. This finding could be due to the tendency of elders with $A D$ to evaluate their perceived oral health better despite showing poor health indicators (26). Also, it has been reported that providing a personalized oral care routine and treatments to elders with $A D$ would prevent the decline in the quality of life of the patient (27). This could be another reason for the high GOHAl scores of the participants with $A D$ in our study since more than half of the cases were having personalized care in their homes.

Decayed, missing, filled teeth index score was not significantly different between the participants with and without $A D$, this finding is in concordance with some studies, where participants had similar age and gender characteristics $(24,28)$. However few studies found higher DMF-T scores in $A D$ patients $(29,30,31)$. The number of teeth was not significantly different between the study groups, this finding is in line with the literature, where the study groups had similar age and gender features $(24,26,32)$.

The periodontal health indicator $\mathrm{Gl}$ was found similar between elders with and without $A D$ in age, gender, and dentate matched study (26), our finding agrees with this literature finding. In this study, we found that the elders with $A D$ had relatively lower $P D$ and $C A L$, and a higher presence of non-periodontitis than the elders without $A D$, these findings are not consistent with the previous studies $(7,32)$. It has been reported that nursing homes need improved oral care services (30), also a study in Turkey reported that the elders in the nursing home had poor oral health (33). Since all participants without $A D$, were residents of the nursing home, they may need more periodontal treatments. Also, the additional analysis showed that elders with $A D$ who had institutional care had higher periodontal indicators of BOP, $P D$, and CAL than those AD patients who had personal care at home. In our study although elders with $A D$ were using higher number of medications that cause dry mouth condition, the study groups had similar USFR levels. This finding is not in agreement with the literature findings of the lower level of salivary flow in elders with $A D(4,7,29)$. However, the effect of dry mouth in our study could be seen in the higher halitosis complaint (34) in elderly people with AD than those elders without AD.

Although it was difficult to perform oral examinations in elders with $A D$, we investigated their oral quality of life with important clinical parameters such as PD, CAL, and dry mouth condition by comparing them with the elders without $A D$, therefore this can be stated as the strengths of our study.

The sample size may be considered relatively small as a limitation of this study, because of impaired memory and capabilities of elders with $A D$, we achieved a sample size greater than 30 in each group, which is the least acceptable sample size for clinical studies.

\section{CONCLUSION}

In conclusion, most of the oral health indicators were found similar between the elders with and without AD. The unfavorable effect of dementia on oral health could be seen in the higher presence of halitosis complaint among the elders with AD. However, periodontal health status of the elders with $A D$ was relatively better than the elders without AD. This might arise from the difference in the type of care the elders received. Also, the education and information provided by Alzheimer's daycare center might help the caregivers to maintain the oral health condition of the patients. This emphasizes the importance of personalized oral care for elders with $A D$ according to their capabilities, needs, and conditions.

\section{Funding}

This research received no external funding.

\section{Conflict of Interest}

The authors declare no conflict of interest.

\section{REFERENCES}

[1] 2020 Alzheimer's disease facts and figures. Alzheimer's and Dementia 2020;16(3) :391-460.

[2] Perkins P, Annegers JF, Doody RS, Cooke N, Aday L, Vernon SW. Incidence and prevalence of dementia in a multiethnic cohort of municipal retirees. Neurology 1997;49(1):44-50.

[3] Fleminger S, Oliver DL, Lovestone S, Rabe-Hesketh S, Giora A. Head injury as a risk factor for Alzheimer's disease: the evidence 10 years on; a partial replication. J Neurol Neurosurg Psychiatry 2003;74(7):857-862.

[4] Gilleard CJ. Is Alzheimer's disease preventable? A review of two decades of epidemiological research. Aging Ment Health 2000;4(2):101-118.

[5] Jablonski RA, Kolanowski A, Therrien B, Mahoney EK, Kassab C, Leslie DL. Reducing care-resistant behaviors during oral hygiene in persons with dementia. BMC Oral Health 2011;11:30.

[6] Chalmers JM, Carter KD, Spencer AJ. Caries incidence and increments in community-living older adults with and without dementia. Gerodontology 2002;19(2):80-94. 
[7] Delwel S, Binnekade TT, Perez RS, Hertogh CM, Scherder EJ, Lobbezoo F. Oral hygiene and oral health in older people with dementia: a comprehensive review with focus on oral soft tissues. Clin Oral Investig 2018;22(1):93-108.

[8] Nordenram G, Ryd-kjellen E, Ericsson K, Winblad B. Dental management of Alzheimer patients. A predictive test of dental cooperation in individualized treatment planning. Acta Odontol Scand 1997;55(3):148-154.

[9] Glossary of Periodontal Terms. 4th ed. Chicago, Illinois: The American Academy of Periodontology; 2001: 39.

[10] Carewska TL, Davies M, West NX: Periodontitis: A potential risk factor for Alzheimer's disease. Br Dent J 2015;218(1):29-34.

[11] Sreebny LM, Schwartz SS. A reference guide to drugs and dry mouth: 2nd edition. Gerodontology 1997;14(1):33-47.

[12] Tonsekar PP, Jiang SS, Yue G. Periodontal disease, tooth loss and dementia: is there a link? A systematic review. Gerodontology 2017; 34: 151-163.

[13] Gil-Montoya JA, Barrios R, Sánchez-Lara I, Carnero-Pardo C, Fornieles-Rubio F, Montes J, Gonzalez-Moles MA, Bravo M. Prevalence of drug-induced xerostomia in older adults with cognitive impairment or dementia: An observational study. Drugs Aging 2016;33(8):611-618.

[14] Ergül S, Akar GC. Reliability and validity of the Geriatric Oral Health Assessment Index in Turkey. J Gerontol Nurs 2008;34(9):33-38.

[15] Folstein MF, Folstein SE, McHugh PR. Mini-mental state. A practical method for grading the cognitive state of patients for the clinician. J Psychiatr Res 1975;12(3):189-198.

[16] Oral health surveys: basic methods 5th edition. WHO; 2013:47-55

[17] WHO handbook for reporting results of cancer treatment. Geneva: WHO; 1979:15-17.

[18] Silness J, Loe H. Periodontal disease in pregnancy. II. correlation between oral hygiene and periodontal condtion. Acta Odontol Scand 1964; 22:121-135.

[19] Loe H, Silness J. Periodontal disease in pregnancy. I. Prevalence and severity. Acta Odontol Scand 1963; 21:533-551.

[20] Eke PI, Page RC, Wei L, Thornton-Evans G, Genco RJ. Update of the case definitions for population-based surveillance of periodontitis. J Periodontol 2012;83(12):1449-54.

[21] Atchison KA, Dolan TA. Development of the Geriatric Oral Health Assessment Index. J Dent Educ 1990;54(11):680-687.
[22] Navazesh M, Kumar SKS. Measuring salivary flow. J Am Dent Assoc 2008:139(2);35S-40S. https://doi.org/10.14219/jada. archive.2008.0353. Accessed September 5, 2020.

[23] Ribeiro GR, Costa JL, Ambrosano GM, Garcia RC. Oral health of elderly with Alzheimer's disease. Oral Surg Oral Med Oral Pathol Oral Radiol 2012;114(3);338-343.

[24] Hatipoglu MG, Kabay SC, Güven G. The clinical evaluation of the oral status in Alzheimer-type dementia patients. Gerodontolgy 2011;28(4):302-306.

[25] Ming Y, Hsu S-W, Yen Y-Y, Lan S-J. Association of oral healthrelated quality of life and Alzheimer disease: A systematic review. J Prosthet Dent 2019;124(2):168-175.

[26] Warren JJ, Chalmers JM, Levy SM, Blanco VL, Ettinger RL. Oral health of persons with and without dementia attending a geriatric clinic. Spec Care Dentist 1997;17(2):47-53.

[27] Marchini L, Ettinger R, Caprio T, Jucan A. Oral health care for patients with Alzheimer's Disease: An update. Spec Care Dentist 2019;39(3):262-273.

[28] Rolim ST, Fabri GMC, Nitrini R, Anghinah R, Teixeira MJ, de Siqueira JT, Cestari JA, de Siqueira SR. Oral infections and orofacial pain in Alzheimer's disease: a case-control study. J Alzheimers Dis 2014;38(4):823-829.

[29] Aragon F, Zea-Sevilla MA, Montero J, Sancho P, Corral R, Tejedor C, Frades-Payo B, Paredes-Gallardo V, Albaladejo A. Oral health in Alzheimer's disease: a multicenter case-control study. Clin Oral Investig 2018;22(9):3061-3070.

[30] Hoben M, Clarke A, Huynh KT, Kobagi N, Kent A, Hu H, Pereira $\mathrm{RAC}$, Xiong T, Yu K, Xiang $\mathrm{H}$, Yoon MN. Barriers and facilitators in providing oral care to nursing home residents, from the perspective of care aides: A systematic review and metaanalysis. Int J Nurs Stud 2017;73:34-51.

[31] Gao SS, Chen KJ, Duangthip D, Lo ECM, Chu CH. The oral health status of Chinese elderly people with and without dementia: A Cross-Sectional Study.Int. J. Environ. Res. Public Health 2020;17(6):1913.

[32] Martande SS, Pradeep AR, Singh SP, Kumari M, Suke DK, Raju AP, Naik SB, Singh P, Guruprasad CN, Chatterji A. Periodontal health condition in patients with Alzheimer's disease. Am J Alzheimers Dis Other Demen 2014;29(6):498-502.

[33] Unlüer S, Gökalp S, Doğan BG. Oral health status of the elderly in a residential home in Turkey. Gerodontology 2007:24(1): 22-29.

[34] Mohammed A.A. Update knowledge of dry mouth - A guideline for dentists. Afr Health Sci 2014;14(3):736-742.

How to cite this article: Cebeci IA, Ozturk D, Dogan B, Bekiroglu N. Assessment of Oral Health in Elders with and without Alzheimer's Disease: A Cross-Sectional Study. Clin Exp Health Sci 2021; 11: 849-855. DOI: 10.33808/clinexphealthsci.983730 